This is the post print version of the article, which has been published in Pediatric Pulmonology,

\title{
Very low asthma death incidence among Finnish children from 1999 to 2015
}

Juho E. Kivistö ${ }^{1,2}$, MD, PhD; Jussi Karjalainen ${ }^{1}, \mathrm{MD}, \mathrm{PhD}$; Laura Kivelä ${ }^{2}$ MD;

Heini Huhtala ${ }^{3}$, M.Sc. and Jennifer L P Protudjer ${ }^{4,5}, \mathrm{PhD}$

Affiliations: ${ }^{1}$ Allergy Centre, Tampere University Hospital Tampere, Finland; ${ }^{2}$ Tampere Centre for Child Health Research, University of Tampere and Tampere University Hospital, Tampere, Finland; ${ }^{3}$ Faculty of Social Sciences, University of Tampere, Tampere, Finland;

${ }^{4}$ Institute of Environmental Medicine, Karolinska Institutet, Stockholm, Sweden; ${ }^{5}$ Center for Occupational and Environmental Medicine, Stockholm, Sweden

Address correspondence to: Juho Kivistö, MD PhD, Allergy Centre, Tampere

University Hospital, PL 2000, 33521 Tampere, Finland [juho.kivisto@uta.fi], Tel:

+35840530 4445, Fax: +35832156057

Funding source: The project has received funding from the Tampere Tuberculosis

Foundation, the Research Foundation of the Pulmonary Diseases, the Emil Aaltonen

Foundation and Väinö and Laina Kivi Foundation.

Key words: asthma, death, child

\section{Abbreviations:}

ICD International Classification of Diseases

ICS Inhaled corticosteroids

IR Incidence rate 


\section{Abstract}

Background: The most recent reports concerning asthma fatalities in Finnish children are from 1998. Since that time, asthma care has improved and asthmarelated hospitalizations have decreased. Yet, it is unknown whether pediatric asthma deaths have similarly decreased.

Objective: To investigate the epidemiology of asthma deaths in the Finnish pediatric population from 1999 onward and to describe the details of fatal asthma exacerbations.

Methods: We obtained copies of the death certificates from Statistics Finland of all Finnish children aged 0 to 19 years who died from asthma between 1999 and 2015. After analyzing the death certificates, the medical records of those with possible asthma death were evaluated in detail to confirm the diagnosis. Incidence rates (IR) of asthma deaths were estimated per 1,000,000 person-years by dividing the number of asthma deaths by the total number of person-years.

Results: Between 1999-2015, there were 6,845 deaths among 0-19-year-old children, of which 21 were possible asthma deaths. Based on patient records and pathological findings, we identified four convincing asthma deaths: aged 7 months, 1 year, 2.5 years and 19 years. None had known allergies or regularly used inhaled corticosteroids. No pre-school or school-aged children died from asthma in Finland between 1999-2015. The cumulative incidence of pediatric asthma deaths was 0.14 per million person-years.

Conclusion: Four Finnish children died from asthma between 1999 and 2015. This corresponds to a total incidence of 0.19 per million person-years. No pre-school or school-aged children died from asthma in Finland during the study period. 


\section{Introduction}

Despite high asthma morbidity, pediatric hospitalizations due to asthma have decreased in many countries ${ }^{1-3}$. Likewise, pediatric asthma mortality has decreased in many countries in recent decades ${ }^{4,5}$, and is now quite rare. However, after epilepsy and intracerebral hemorrhage, asthma is the third most common non-cardiac cause of sudden death in young people ${ }^{6}$. Further, mortality rates for asthma may have been underestimated in national mortality reports, based on the underlying cause mortality ${ }^{7}$

In Finland, we previously reported on the decreasing trends of pediatric hospitalizations due to asthma and allergic reactions ${ }^{3,8}$. The absence of anaphylaxis deaths among children in Finland between 1996 and 2013 has been partly attributed to good asthma care among the pediatric population in the country ${ }^{9,10}$.

Fatal asthma exacerbations between 1976 and 1998 in Finland were examined and published nearly a decade ago in this journal. Malmström et al reported a low incidence of pediatric asthma-related deaths, ranging between 0.0 to 3.5 per million person-years ${ }^{11}$. Although the burden of asthma in Finland has lightened during the $21^{\text {st }}$ century, it is unknown whether pediatric asthma deaths have similarly decreased 3.

To this end, we now aim to investigate the epidemiology of asthma deaths in the Finnish pediatric population from 1999 onward and to describe the details of fatal asthma exacerbations. 


\section{Methods}

This study is based on 1) the death certificates that form the basis of the Finnish Official Cause-of-Death Database and 2) full patient records ${ }^{12}$. Since 1936, death certificates have been collected by Statistics Finland. Since 1969, both classified mortality statistics and death certificates have been available in electronic form ${ }^{13}$. In Finland, the determination of the cause-of-death is based on medical- or forensic evidence. The Finnish Official Cause-of-Death Statistics are, in practice, 100\% complete, as each death, its certificate and corresponding personal information in the Finnish computerised population register are cross-checked ${ }^{12,14}$. The accuracy of the asthma death certificates and their cause-of-death codes are further verified by autopsies performed in $94 \%$ to $97 \%$ of these deaths ${ }^{13,14}$. The cause-of-death codes used are based on the International Classification of Diseases (ICD) ${ }^{15}$. In this study, we included death certificates during the time period of 1999 to 2015.

We obtained copies of the death certificates from Statistics Finland of all Finnish children aged 0 to 19 years who died from asthma between 1999 and 2015 . The search was performed by Statistics Finland using ICD-codes J45 and J46 for asthma. Codes J20-J22 (acute bronchitis, acute bronchiolitis and unspecified acute lower respiratory infection) were also included to ensure that all fatal asthma cases will be identified. (Table 1)

All potential death certificates were analyzed by the corresponding author. Cases in which asthma was considered to be even a possible cause of death were screened thoroughly by expert board of three independent assessors (Kivistö, Karjalainen and Kivelä). Patient records of these cases were retrospectively reviewed for details 
relating to asthma death, including treatments in primary care and hospital, as well as pathological findings. Permission to use information of patient records was granted by the National Institute for Health and Welfare in Finland.

In order to compute the incidence of pediatric asthma deaths in Finland, the annual age-specific populations were obtained from Official Statistics of Finland ${ }^{16}$. The incidence of deaths due to asthma (per 1,000,000 persons) was based on the results of the entire population of children in Finland, rather than cohort- or sample-based estimates. Incidence rates (IR) of asthma deaths were estimated per 1,000,000 person-years by dividing the number of asthma deaths by the total number of personyears. Consequently, $95 \%$ confidence intervals were not calculated. 


\section{Results}

During the 16-year study period, there was a total of 6,845 deaths among 0-19-yearold children, of which 21 were possible asthma deaths. After reviewing patient records and pathological findings, we found four convincing asthma deaths in this age group between 1999 and 2015 (Table 2). The annual incidence of pediatric asthma deaths varied from 0.0 to 0.83 per million person-years. The cumulative incidence of asthma deaths was 0.19 per million person-years during the study period.

In the preliminary stage, 14 patients were excluded due to under 3 months of age, severe disability (e.g. tetraplegia), severe mental retardation and/ or institutional care (Table 2). An asthma diagnosis or clear evidence of obstructive episode(s) prior to death AND pathological findings referring to fatal asthma were needed to confirm death caused by asthma.

The four patients who died from asthma were aged 7 months, 1 year 1 month, 2.5 years and 19 years (Table 3). No pre-school or school-aged children died from asthma in Finland between 1999 and 2015.

None of the patients who died from asthma regularly used inhaled corticosteroids (ICS) for treatment before the fatal episode and none had any known allergies. Two of the deaths occurred in January, one in September and one in December.

Three patients of four suffered from respiratory infection prior to death. Pathological findings referring to asthma were observed in all these patients (Table 3). All patients 
had bronchioles filled by mucus along with the pulmonary changes connected to asthma bronchiale or obstructive bronchitis.

The first fatal pediatric asthma patient during the study period was a 7-month-old girl who suffered from symptoms connected to laryngitis. Subsequently, she had more breathing problems that were more likely to have been obstructive bronchitis than laryngitis. She was given oxygen flow and then suddenly had severe difficulty in breathing. She was intubated and resuscitated. However, these measures were inadequate to save her. Macroscopic and histologic findings confirmed the death caused by asthmatic obstruction (Table 3 ).

The second patient was 1 year 1 month old girl who had an asthma diagnosis but was not receiving regular medication. She suffered from cough during the days before her death. She slept restlessly and some rhoncus was heard by the parents who found the girl lifeless in her bed. Resuscitation was ineffective. Macroscopic and histologic pathological findings in the lungs confirmed the death caused by asthma (Table 3).

The third patient was 2 year, 6 month old boy who was taken to hospital due to obstructive breathing. He was treated with inhaled salbutamol, per guidelines. However, his breathing became more difficult and he required oxygen flow. He was also given intramuscular epinephrine and needed to be intubated. Respirator treatment was inadequate. Resuscitation was ineffective. Pathological findings confirmed asthma as the cause of death (Table 3). 
The fourth patient was a 19-year-old boy who had an asthma diagnosis, and who occasionally use of short-acting $\beta 2$-adrenergic receptor agonists, but no continuous medication. He was found dead in bed in the morning. He had consumed alcohol during the preceding night, but the macroscopic and histologic pathological findings in the lungs confirmed the death caused by asthma (Table 3). 


\section{Discussion}

Between 1999 to 2015, four Finnish children died as a result of asthma. This represents a total incidence of 0.19 per million person-years. The annual incidence of pediatric asthma deaths varied from 0.0 to 0.83 per million person-years. None of the children who died from to asthma regularly used ICS before the fatal episode. No pre-school or school-aged children in Finland died from asthma during the study period.

Previous estimates of asthma-related deaths in children have ranged between 0.5-20 per million ${ }^{4,17}$. In Finland, the incidence of asthma deaths among 0-19-year-old children was low during 1976-1998 (3.5 per million person-years at highest). Compared to these earlier numbers, our present findings suggest that the incidence between 1999 and 2015 was extremely low (0.19 per million person-years). It is possible that the Finnish Asthma and Allergy Programmes during 1994-2004 and 2008-2018, respectively, may have reduced the asthma death deaths by focusing on early intervention and disease control ${ }^{10,18}$.

This study provides important information on the trends in pediatric asthma deaths in a well-defined population across a period of 16 years. Internationally, corresponding studies investigating the secular trends of fatal asthma among children and adolescents are scarce ${ }^{4}$. Another strength of this study is that it presents nationwide data as the death certificates related to pediatric asthma were drawn from the whole country. Furthermore, despite the fact that The Finnish Official Cause-of-Death Statistics are, in practice, $100 \%$ complete, as each death, its certificate and corresponding personal information in the Finnish computerized population register 
are cross-checked ${ }^{12,14}$, we analyzed all the potential patient records once more to certify that no asthma deaths were missed or incorrectly diagnosed.

The present study has also some limitations. First, to our knowledge there are no convincing pathologic findings to certify the death as asthma and not bronchiolitis. Thus, it is possible that our very low incidence is overestimate. Second, an asthma attack or obstructive episode is sometimes an unclear event, and may include symptoms connected to other diseases (e.g. laryngitis). Furthermore, as the study was based on the retrospective research frame, some information on the circumstances surrounding the asthma deaths may be somewhat limited. However, the accuracy of the death certificates and their cause-of-death codes are further verified by autopsies performed on $94 \%$ to $97 \%$ of these deaths in Finland ${ }^{14}$. Moreover, we analyzed all patient records over again and asthma diagnosis or clear evidence of obstructive episode prior to death along with the pathological findings referring to fatal asthma were needed to confirm death caused by asthma.

Previously, we showed that the incidence of pediatric asthma hospitalizations has decreased in Finland by half during $2005-2014^{3}$. A similar decrease was not seen in the neighboring country of Sweden ${ }^{3}$. Although the reasons for the differences between countries have not been completely clear, it has been discussed whether there are differences between fatal outcomes among asthmatic children. Swedish asthma mortality rates among children and young adults has been low 0.53 per million person-years ${ }^{4}$. The present study shows that in Finland the incidence of asthma deaths among children is extremely low and supports the theory that despite 
the declining trends of hospitalizations, it seems not that Finnish children are discharged too early from emergency departments leading to fatal outcomes.

Uncontrolled asthma is a known risk factor for asthma death in young people ${ }^{19}$. Allergy, especially food allergy, is an independent risk factor for potentially fatal childhood asthma ${ }^{4,20}$. Pollen season may also increase pediatric asthma deaths by inreasing allergic reactions ${ }^{8,11}$. In the present study, however, none of the patients were known to suffer from allergies and fatal cases occurred outside the pollen season. A previous study from United States showed that asthma mortality peaks in winter months, and that respiratory tract infections may be a risk factor for asthma death ${ }^{21}$. In the present study, fatalities occurred during autumn-winter months and all young children who died due to asthma had concomitant respiratory tract infections.

We previously showed an absence of anaphylaxis-related pediatric deaths in Finland between 1996 and $2013^{15}$. It has been discussed whether high-quality asthma care in Finland may be attributable to low rate in anaphylaxis deaths among pediatric population ${ }^{10}$. However, earlier there has been no evidence of low fatal asthma incidence among pediatric population during the $21^{\text {st }}$ century. This study strengthens the evidence of exhaustive asthma care in Finland among pediatric population ${ }^{22}$.

In conclusion, a total of four Finnish children died from asthma between 1999 and 2015. This corresponds to a total incidence of 0.19 per million person-years. No preschool or school-aged children died from due to asthma in Finland during the study period. 


\section{Acknowledgements}

This study was funded by the Tampere Tuberculosis Foundation, the Research Foundation of the Pulmonary Diseases, the Emil Aaltonen Foundation and Väinö and Laina Kivi Foundation. We want express our humble gratitude for the supporters. We thank Mikko Hirvonen, Juhani Lehtola, Panu Peitsaro, Sami Remes, Arja Tomminen, Maija Tuominen, and Tiina Reijonen for their help to find the patient records. 


\section{References}

1. de Miguel-Diez J, Jimenez-Garcia R, Hernandez-Barrera V, Lopez de Andres A, Villa-Asensi JR, Plaza V, et al. National trends in hospital admissions for asthma exacerbations among pediatric and young adult population in Spain (2002-2010). Respir Med 2014; 108:983-91.

2. Hasegawa K, Tsugawa Y, Brown DF, Camargo CA, Jr. Childhood asthma hospitalizations in the United States, 2000-2009. J Pediatr 2013; 163:1127-33 e3.

3. Kivisto JE, Protudjer JL, Karjalainen J, Bergstrom A, Korppi M. Trends in paediatric asthma hospitalisations - differences between neighbouring countries. Thorax 2017.

4. Bergstrom SE, Boman G, Eriksson L, Formgren H, Foucard T, Horte LG, et al. Asthma mortality among Swedish children and young adults, a 10-year study. Respir Med 2008; 102:1335-41.

5. Kaur B, Butland B. Trends in asthma mortality. Asthma mortality is falling in most age groups in Scotland. BMJ 1997; 315:1014.

6. Puranik R, Chow CK, Duflou JA, Kilborn MJ, McGuire MA. Sudden death in the young. Heart Rhythm 2005; 2:1277-82.

7. Goldacre MJ, Duncan ME, Griffith M. Death rates for asthma in English populations 1979-2007: comparison of underlying cause and all certified causes. Public Health 2012; 126:386-93.

8. Kivisto JE, Protudjer JL, Karjalainen J, Wickman M, Bergstrom A, Mattila VM. Hospitalizations due to allergic reactions in Finnish and Swedish children during 1999-2011. Allergy 2016; 71:677-83.

9. Kivisto JE, Dunder T, Protudjer JL, Karjalainen J, Huhtala H, Makela MJ. Adult but no pediatric anaphylaxis-related deaths in the Finnish population from 1996 to 2013. J Allergy Clin Immunol 2016; 138:630-2.

10. Kauppi P, Linna M, Martikainen J, Makela MJ, Haahtela T. Follow-up of the Finnish Asthma Programme 2000-2010: reduction of hospital burden needs risk group rethinking. Thorax 2013; 68:292-3.

11. Malmstrom K, Kaila M, Kajosaari M, Syvanen P, Juntunen-Backman K. Fatal asthma in Finnish children and adolescents 1976-1998: validity of death certificates and a clinical description. Pediatr Pulmonol 2007; 42:210-5.

12. Official Statistics of Finland. Structure of Population and Vital Statistics: Whole Country and Provinces, 2006 ed. Helsinki: Statistics Finland; 2006.

13. Official Cause of Death Statistics. Helsinki 2005: Statistics Finland; 2005.

14. Kannus P, Parkkari J, Koskinen S, Niemi S, Palvanen M, Järvinen M, et al. Fallinduced injuries and deaths among older adults. JAMA 1999; 281:1895-9.

15. International Statistical Classification of Diseases and Related Health Problems, 10th Revision. Geneva: World Health Organization; 1992.

16. Official Statistics of Finland. Structure of Population and Vital Statistics: Whole Country and Provinces, 2014 ed. Helsinki: Statistics Finland; 2014.

17. Sears MR. Worldwide trends in asthma mortality. Bull Int Union Tuberc Lung Dis 1991; 66:79-83. 
18. Pelkonen AS, Kuitunen M, Dunder T, Reijonen T, Valovirta E, Makela MJ, et al. Allergy in children: practical recommendations of the Finnish Allergy Programme 2008-2018 for prevention, diagnosis, and treatment. Pediatr Allergy Immunol 2012; 23:103-16.

19. Gullach AJ, Risgaard B, Lynge TH, Jabbari R, Glinge C, Haunso S, et al. Sudden death in young persons with uncontrolled asthma--a nationwide cohort study in Denmark. BMC Pulm Med 2015; 15:35.

20. Vogel NM, Katz HT, Lopez R, Lang DM. Food allergy is associated with potentially fatal childhood asthma. J Asthma 2008; 45:862-6.

21. McCoy L, Redelings M, Sorvillo F, Simon P. A multiple cause-of-death analysis of asthma mortality in the United States, 1990-2001. J Asthma 2005; 42:757-63.

22. Haahtela T, Herse F, Karjalainen J, Klaukka T, Linna M, Leskela RL, et al. The Finnish experience to save asthma costs by improving care in 1987-2013. J Allergy Clin Immunol 2017; 139:408-14 e2. 
Table 1. ICD-codes searched for asthma deaths.

\section{ICD-code Meaning}

J20 Acute bronchitis

J21 Acute bronchiolitis

J22 Unspecified acute lower respiratory infection

J45 Asthma

J46 Status asthmaticus 
Table 2. Search process: Fatal asthma among 0-19-year-old Finnish children during 19992015.

Total 6845 deaths in age group

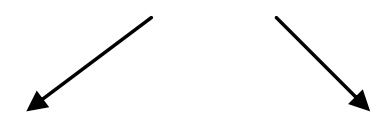

Excluded:

6824 other deaths

Included:

21 possible asthma deaths
Excluded after preliminary review: 14 death certificates

- age under 3 months (3)

- severe disability (7)

- severe mental retardation (2)

- institutional care (2)
Included after review:

7 death certificates

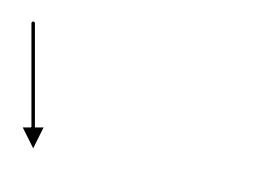

Full review of patient records by three practicing authors (JKi, JKa and LKi)
Excluded after review:

3 patients with other cause of death

- Girl 5 mo, infection, cardiac abnormality, not clear evidence of obstruction or asthma

- Girl 1yr 3mo, main symptoms high fever and convulsions, no autopsy

- Boy 1 yr 3 mo, respiratory infection with septic symptoms, no evidence of obstruction or asthma 
Table 3. Characteristics of the three verified asthma deaths among Finnish children during 1999-2015 (ICS= Inhaled corticosteroid, ICU= Intensive Care Unit).

\begin{tabular}{|c|c|c|c|c|}
\hline & $\mathrm{A}$ & $\mathrm{B}$ & $\mathrm{C}$ & $\mathrm{D}$ \\
\hline Age & 7 months & 1 year 1 month & 2.5 years & 19 years \\
\hline Gender & Female & Female & Male & Male \\
\hline ICS & No & No & No & No \\
\hline $\begin{array}{l}\text { Respiratory } \\
\text { infection }\end{array}$ & Yes & Yes & Yes & No \\
\hline Treated in ICU & Yes & No & Yes & No \\
\hline Respirator & Yes & No & Yes & No \\
\hline Resuscitation & Yes & Yes & Yes & No \\
\hline Pathological findings & Bronchial mucus & $\begin{array}{l}\text { Bronchial } \\
\text { mucus }\end{array}$ & $\begin{array}{l}\text { Bronchial } \\
\text { mucus }\end{array}$ & $\begin{array}{l}\text { Bronchial wall } \\
\text { thickening, mucus }\end{array}$ \\
\hline Histology & $\begin{array}{l}\text { Neutrophils, } \\
\text { few eosinophils }\end{array}$ & $\begin{array}{l}\text { Neutrophils } \\
\text { and } \\
\text { eosinophils, } \\
\text { chronic } \\
\text { inflammation }\end{array}$ & $\begin{array}{l}\text { Chronic } \\
\text { inflammatio } \\
\mathrm{n}\end{array}$ & Lymphocytes \\
\hline $\begin{array}{l}\text { Pathological } \\
\text { statement }\end{array}$ & $\begin{array}{l}\text { Obstructive } \\
\text { bronchitis }\end{array}$ & $\begin{array}{l}\text { Asthma } \\
\text { bronchiale }\end{array}$ & $\begin{array}{l}\text { Obstructive } \\
\text { bronchitis }\end{array}$ & Asthma bronchiale \\
\hline
\end{tabular}

